Tjalling C. Koopmans Research Institute Tplligl Aoopman

Discussion Paper Series nr: 08-35

\title{
The Economics of Crime and Money Laundering: Does Anti-Money Laundering Policy Reduce Crime?
}

Joras Ferwerda 


\section{Tjalling C. Koopmans Research Institute Utrecht School of Economics \\ Utrecht University}

Janskerkhof 12

3512 BL Utrecht

The Netherlands

telephone $\quad+31302539800$

fax $\quad+31302537373$

website www.koopmansinstitute.uu.nl

The Tjalling C. Koopmans Institute is the research institute and research school of Utrecht School of Economics.

It was founded in 2003, and named after Professor Tjalling C. Koopmans, Dutch-born Nobel Prize laureate in economics of 1975.

In the discussion papers series the Koopmans Institute publishes results of ongoing research for early dissemination of research results, and to enhance discussion with colleagues.

Please send any comments and suggestions on the Koopmans institute, or this series to J.M.vanDort@uu.nl

ontwerp voorblad: WRIK Utrecht

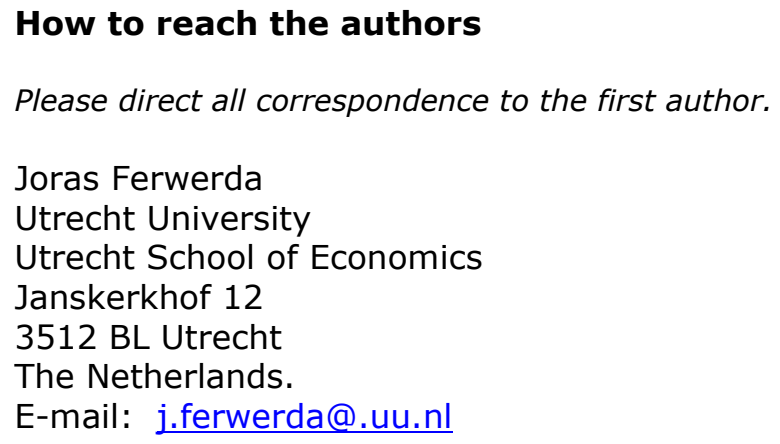

This paper can be downloaded at: http://www.koopmansinstitute.uu.nl 
Utrecht School of Economics

Tjalling C. Koopmans Research Institute

Discussion Paper Series 08-35

\title{
The Economics of Crime and Money Laundering: Does Anti-Money Laundering Policy Reduce Crime?
}

\author{
Joras Ferwerda \\ Utrecht School of Economics \\ Utrecht University
}

November 2008

\begin{abstract}
Anti-money laundering policy has become a major issue in the Western world, especially in the United States after 9-11. Basically all countries in the world are more or less forced to cooperate in the global fight against money laundering. In this paper, the criminalization of money laundering is modelled, assuming rational behaviour of criminals, following the law and economics strand of the literature which is described as the economics of crime. The theoretical model shows that a) the probability to be caught for money laundering, b) the sentence for money laundering, c) the probability to be convicted for the predicate crime and d) the transaction costs of money laundering are negatively related to the amount of crime. Under the assumption that these factors are all positively influenced by a stricter anti-money laundering policy, the hypothesis empirically tested in this paper is that anti-money laundering policy deters potential criminals from illegal behavior and therefore lowers the crime rate. Since the data on anti-money laundering policy, used in the literature so far, is not all-embracing, a new unique indicator is constructed by using all the information from the mutual evaluation reports on money laundering of the FATF, IMF and World Bank. This unique dataset is used in an empirical estimation based on a Mundlak specification to test the effect of antimoney laundering policy on the crime rate. Among the four policy areas measured the role of laws, the institutional framework, the duties of the private sector in law enforcement, and international cooperation, the latter turned out to be the most important policy area for reducing crime. This should be an extra incentive for countries and international organizations to continue their efforts to promote and develop international cooperation in the fight against money laundering.
\end{abstract}

Keywords: Anti-Money Laundering Policy and Crime

JEL classification: K42, F59

Acknowledgements

I would like to thank Silvester Bosma for his cooperation in developing the database, Brigitte Unger (Utrecht University School of Economics) for supervising the paper, Marco Arnone

(Catholic University of Milan, Italy; former member of the IMF) for inspiring the creation of the database and Peter-Jan Engelen, Bas van Groezen and Loek Groot (Utrecht University School of Economics) for discussing the paper. 


\section{Introduction}

The economic proceeds from crime are the same as the proceeds from legal activities with one important difference: they cannot be spent as easily. Money laundering is (at least to some extent) needed in order to spend the money derived from illegal activities. The term 'money laundering' is derived from the gangster $\mathrm{Al}$ Capone, who funnelled his ill-gotten gains through launderettes to make it appear legal. (van Duyne, 2003, p. 73) Nowadays, governments are still fighting (the consequences of) money laundering. The statement at the October 1996 Annual Meetings in Washington D.C. of the International Monetary Fund's (IMF) Interim Committee-its highest decision-making authority-featured money laundering as one of the most serious issues facing the international financial community (Camdessus, 1998). The necessary coexistence with crime makes money laundering harmful (Takáts, 2006). Since crime is on the top of many nations' domestic policy agendas, there is a need for a body of policy-relevant knowledge about crime, for theoretical ideas and empirical findings that can be translated into public debate and relevant policies. (DiIulio, 1996, p.3) Reviewing the empirical literature on money laundering, Unger (2006, p.102) concludes: "Most literature on money laundering effects is pure speculation. Some of the literature refers to estimates without ever mentioning the source. [... Furthermore, [... one source refers to the other source, without much of an empirical solid back up." This paper tries to add a theoretical and empirical insight in the effects of (the fight against) money laundering to the current literature.

The paper starts with creating a theoretical model which describes how the criminalization of money laundering has a negative effect on the crime rate. The starting point of this theory is the 'economics of crime', which explains criminal behaviour on the assumption of rational choice (see Bentham, [1788] 1843, Becker, 1968 and for a good overview of the literature on this research area Eide, 2000). Extending this model by including the effect of money laundering shows that anti-money laundering policy deters potential criminals to commit not only the illegal act of laundering money, but crimes in general.

Extensive data on anti-money laundering policies, that can be used for a cross-country analysis, is still missing in the current literature. Therefore an indicator is developed in this paper, based on all the available information on anti-money laundering policies in the mutual evaluation reports of the Financial Action Task Force (FATF), the IMF and the World Bank. This results in a unique indicator which encompasses several aspects of anti-money laundering policy. The creation of this indicator gives the possibility to test the suspected and 
guessed effects of money laundering (policies), which is needed (Dilulio, 1996, p.3) and lacking (Unger, 2006, p.102) at the moment. The last part of the paper tests whether the hypothesis of the economics of crime on money laundering can be confirmed econometrically.

\section{The economics of crime}

The idea of the economics of crime was first mentioned by Bentham ([1788] 1843, p. 399):

'The profit of the crime is the force which urges man to delinquency: the pain of the punishment is the force employed to restrain him form it. If the first of these forces be the greater, the crime will be committed; if the second, the crime will not be committed'

This idea, which later became known as 'the economics of crime', was used and modernized by Gary S. Becker in 1968. His paper 'Crime and Punishment: An Economic Approach' suggests that governments should develop a policy system where 'crime does not pay'. It is the task of the government to assure that the costs of committing each crime (the chance to get caught times the amount of punishment), are higher then the benefits of each crime. If this is the case, the punishment will deter the criminal from committing the specific crime. This follows the economists' usual analysis of choice and assumes that a person commits an offence if the expected utility exceeds the utility he could get otherwise. Some persons become 'criminals', not because their basic motivation differs, but because their benefits and costs of crime differ. (Becker, 1968, p.176) So whether a person will perform a specific criminal act or not depends on his probability of conviction $\left(p_{j}\right)$, to his punishment if convicted $\left(f_{j}\right)$ and to other variables, such as income available to him in legal and other illegal activities, the frequency of nuisance arrests and his willingness to commit an illegal act. Becker (1968, p. 177) describes the expected utility of committing an offence as;

$$
E U_{j}=p_{j} U_{j}\left(Y_{j}-f_{j}\right)+\left(1-p_{j}\right) U_{j}\left(Y_{j}\right)
$$

with $E U_{j}$ as the expected utility from committing an offence, $U_{j}$ as a utility function and $Y_{j}$ the income, monetary plus psychic, from committing an offence. This means that a higher probability of conviction and a more severe punishment would lower the expected utility as long as the marginal utility of income is positive. (Becker, 1968, p.177) For the step from this micro perspective to the macro perspective, Becker understands the differences between 
persons in the determinants $p, f$ and $u^{l}$, but considers only their averages for the sake of simplicity. This means that one can explain the amount of offences $(O)$ in the market with the following reduced form, called the 'market offence function';

$$
O=O(p, f, u)
$$

This means that the amount of crime decreases when the probability of conviction goes up or when local governments punish criminal behaviour more intensely.

After an extensive review of the empirical studies on the 'economics of crime' Eide (2000, p.360) concludes that, as a whole, the empirical studies in this field indicate a negative association between crime and the probability and severity of punishment and that this result may be regarded as a confirmation that an increase in the probability or severity of punishment will decrease the expected utility of criminal acts and thereby the level of crime.

The economics of crime models the effects on crime in general. With the recent expansion of the types of crime, more specifically the development of financial crimes like money laundering, the economics of crime has to be extended to the 'economics of crime and money laundering'.

\section{The Economics of Crime and Money Laundering}

Since money laundering is an illegal act and the only way to be able to use one's ill-gotten gains in the legal economy, it is necessary to commit two criminal acts (with both its own probability of conviction and sentence) to profit from criminal behaviour: the crime itself and money laundering of the proceeds of crime. ${ }^{2}$ This means that a criminal faces two instances of probable conviction and two different potential punishments. When an individual commits a crime to profit from it, he has the risk to be caught $(p)$ and be punished $\left(f_{o}\right)$. However, when he could not use his profit before laundering it, he faces again the chance to be caught $(q)$ and be punished for laundering money $\left(f_{m l}\right)$, and then facing the chance to get convicted for committing the original crime $(z)^{3}$. In addition to this, each money laundering operation

\footnotetext{
${ }^{1} u$ are all other influences determining the expected utility of crime

${ }^{2}$ In practice not all the proceeds from crime have to be laundered. For simplicity it is assumed that this is incorporated in the probability to get convicted for money laundering (q), which can be zero if the initial offence is not a predicate crime for money laundering and will reduce the model to the original model of Becker (1968). ${ }^{3}$ Police forces nowadays try to convict the criminal not only for the act of money laundering, but they also try to prove the original act, which is in most cases already necessary to prove the act of money laundering. Not all criminals launder the money themselves. Not laundering the gains from a criminal act normally leads to higher transaction costs, but a lower chance to get caught, for money laundering and for the original crime. A criminal
} 
implies aggregate transaction costs $(t c)$, represented by the resources a criminal needs in order to put the money laundering process into action. On the one hand, we have technical costs related to the adopted money laundering technology; on the other hand, we have costs due to anti-money laundering regulation. The costs of money laundering will therefore depend on the effectiveness of anti-money laundering regulation: the more effective, the more expensive it will be for criminals to undertake the activity of money laundering. The two types of costs may obviously be related in a more of less significant fashion (based on Masciandaro, 1999, p.227) To model the above-mentioned reasoning, the model Becker (1968) presented on the expected utility of criminal behaviour and the supply of offences is adjusted.

Figure 1. The sequential possibilities for a criminal and the corresponding utilities

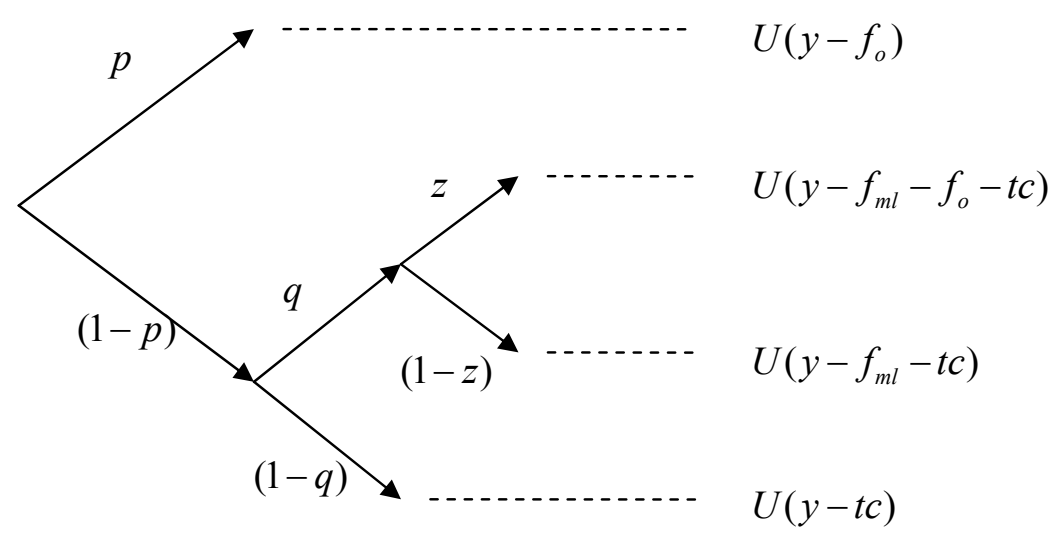

Figure 1 is used to calculate the expected utility received by the potential criminal for a specific criminal act (see equation 3 ).

$$
\begin{array}{r}
E U=p U\left(y-f_{o}\right)+(1-p) q z U\left(y-f_{m l}-f_{o}-t c\right)+(1-p) q(1-z) U\left(y-f_{m l}-t c\right) \\
+(1-p)(1-q) U(y-t c)
\end{array}
$$

If positive marginal utility from income is assumed it can be shown that

$$
\begin{aligned}
& \partial E U / \partial p=U\left(y-f_{o}\right)-q z U\left(Y-f_{m l}-f_{o}-t c\right)-q(1-z) U\left(Y-f_{m l}-t c\right) \\
& -(1-q) U(y-t c)<0
\end{aligned}
$$

with ill gotten gains faces a trade-off here, and although this is an interesting part of the decision making process of a criminal, this is not incorporated in detail in the model. 


$$
\begin{aligned}
& \partial E U / \partial q=(1-p) z U\left(y-f_{m l}-f_{o}-t c\right)+(1-p)(1-z) U\left(y-f_{m l}-t c\right) \\
& -(1-p) U(y-t c)<0 \\
& \partial E U / \partial z=(1-p) q U\left(y-f_{m l}-f_{o}-t c\right)-(1-p) q U\left(y-f_{m l}-t c\right)<0 \\
& \partial E U / \partial f_{o}=-(1-p) q z U^{\prime}\left(y-f_{m l}-f_{o}-t c\right)-(1-p) q(1-z) U^{\prime}\left(y-f_{m l}-t c\right)<0 \\
& \partial E U / \partial f_{m l}=-(1-p) q z U^{\prime}\left(y-f_{m l}-f_{o}-t c\right)-(1-p) q(1-z) U^{\prime}\left(y-f_{m l}-t c\right)<0 \\
& \partial E U / \partial t c=-(1-p) q z U^{\prime}\left(y-f_{m l}-f_{o}-t c\right)-(1-p) q(1-z) U^{\prime}\left(y-f_{m l}-t c\right) \\
& -(1-p)(1-q) U^{\prime}(y-t c)<0
\end{aligned}
$$

with $E U$ as the expected utility gained from a criminal act, $U$ as a (von NeumannMorgenstern) utility function ${ }^{4}, p$ as the probability of conviction for the initial offence ${ }^{5}$ (the predicate crime), $f_{o}$ as the monetary equivalent of the punishment ${ }^{6}$ if convicted for the initial offence, $q$ as the probability of conviction for money laundering, $f_{m l}$ as the monetary equivalent of the punishment if convicted for the money laundering offence, $z$ as the probability of conviction for the initial offence - the predicate crime - after money laundering is detected and $t c$ as the transaction costs of laundering the money ${ }^{7}$.

By using the averages of all the values for $p, f_{o}, q, f_{m l}, z$ and $t c$ (like Becker, 1968), the 'market offence function' can be presented, in reduced form, as:

$$
O=O\left(\bar{p}, \overline{f_{o}}, \bar{q}, \overline{f_{m l}}, \bar{z}, \overline{t c}, \bar{u}\right)
$$

\footnotetext{
${ }^{4}$ Von Neumann-Morgenstern utility functions are commonly used in economics to make calculations with the utility functions easier.

${ }^{5}$ In this model, the offences are split into two categories; money laundering and all other offences. With 'initial offence' 'all offences except money laundering' is meant.

${ }^{6}$ The monetary equivalent of the punishment

${ }^{7}$ It has to be remarked here that these transaction costs could be the rewards for other persons and therefore an incentive to become a money launderer. This could have its effect on the expected value of laundering money, which could have an effect on the number individuals that prefer the illegal act of money laundering above other, (il)legal acts. The number of offences in this model excludes the illegal act of money laundering, so this relation does not blur the model.
} 
with $O$ as the total number of offences (excluding money laundering ${ }^{8}$ ) and $u$ as the average of all other influences.

The relation of all the factors in the 'market offence function' is shown to be negative by equations (4) till (9), except for $u$. Equation 11 describes these relations, four of these $\left(q, f_{m l}\right.$, $z$ and $t c$ ) will be used as the hypothesis for the empirical estimation (these relations are shown in figure 2).

$$
\begin{array}{r}
O=O\left(\bar{p}, \overline{f_{o}}, \bar{q}, \overline{f_{m l}}, \bar{z}, \overline{t c}, \bar{u}\right) \\
(-)(-)(-)(-)(-)(-)( \pm)
\end{array}
$$

\section{Crime data}

Since crime is, by definition, an illegal act, it is likely that every method used to measure the actual amount (or level) of crime is inaccurate. There are many kinds of crime statistics, but basically they can be divided into two groups of statistics: police recorded and based on victim surveys. The first is the amount of crime detected by the police or similar law enforcement agencies. The most reliable sources for this kind of data are the European Sourcebook of Crime and Criminal Justice Statistics and the crime statistics gathered by Interpol and the United Nations. The latter, victim surveys, are statistics that are gathered by interviewing households or individuals trying to detect the victims of crime. The most reliable statistic of this kind is the International Crime Victims Survey (ICVS).

Both kinds of data have their advantages and disadvantages. Police recorded crime statistics are often readily available and are reliable in terms of the right classification of the crime and are not biased by the perceptions of individuals. The downside is that these crime statistics are only measuring the amounts of caught crime, which means that crime is always underestimated. However, this will not damage the empirical research if the rate at which actual crimes are reported is constant across countries and years. This seems to be an implicit assumption in most studies in this research field. (Eide, 2000, p.366) The crimes that are considered as minor relevance by the police (officers) might be even further underestimated, because there is less attention for these crimes. The differences in these crimes statistics

\footnotetext{
${ }^{8}$ The analysis on the economics of crime and money laundering stated the assumption that money laundering is illegal; this would double the amount of illegal acts if the profit from every crime will be laundered. This will blur the picture, and therefore, the word offences will be used, that must de read as excluding the illegal act of money laundering.
} 
(between years or geographical areas) might be the result of a difference in productivity of the law enforcement agencies, instead of a difference in the real amount of crime.

In victim surveys the productivity of the law enforcement does not influence the statistics. The downside of victim surveys are that people are asked whether they have been a victim of a crime in a certain period, while evidence that these crimes actually occurred are not needed. This means that what is measured is not the actual amount of crime, but the perceived amount of what is believed (by the interviewed) to be crime. For my research the two most striking problems are that the measured crimes are not at all the crimes which are normally related to money laundering and these statistics are much less available than the police recorded crime statistics. ${ }^{9}$

My conclusion is that for this research, police recorded crime statistics are the best possible proxy for crime since it is more available and includes more crimes that are relevant for money laundering, which is in line with most of the studies in this research field. (Eide, 2000, p. 366) For this research, the European Sourcebook of Crime and Criminal Justice Statistics is used, since it has comparable data on almost all of the countries in the dataset. ${ }^{10}$ The selected countries are all developed countries, with many of them in the same region (Europe). It is assumed that this reduces the bias of differences in productivity of law enforcement agencies, though differences among different law systems within Europe might prevail.

\section{Data on Anti-Money Laundering Policy}

The specific values of the chance to get caught for money laundering $(q)$ and the predicate crime $(z)$, the average sentence for money laundering $\left(f_{m l}\right)$ and the transactions costs $(t c)$ are not well documented or available. To be able to test the theoretical model above (the economics of crime and money laundering) it is assumed that a stricter anti-money laundering policy increases: simultanously the probability to convict someone for money laundering, the penalty for convicted money launderers, the probability that the money launderer is also convicted for the predicate crime and the transaction costs of money laundering (as done by Masciandaro, 1999, p.227). The relation between anti-money laundering policy and crime is shown in figure 2.

\footnotetext{
${ }^{9}$ ICVS has traditionally focused on crimes against individuals and households, and doesn't have much to say about buyer-seller crimes like drug trafficking and product counterfeiting, or about crimes against businesses, including fraud and insider trading. I owe this point to John Walker, CEO of Crime Trend Analysis, one of the world's leading crime trend experts.

${ }^{10}$ To get a balanced panel the missing values are interpolated partly by using statistics on different years of the same country and partly by using UNODC crime statistics, which are comparable to some extent.
} 
Figure 2. The indirect relation between anti-money laundering policy and crime

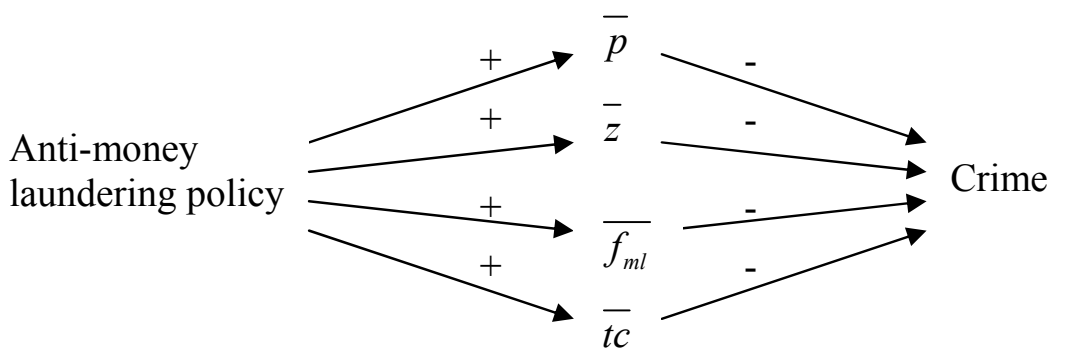

The positive relation between anti-money laundering policy and the four important deterrences for laundering money is assumed, while the negative relation between these deterrences are shown-respectively from top to bottom - by equation (5), (6), (8) and (9).

So far the deterrences for money launderers are measured by specific indicators: low bank secrecy laws (see Walker, 1999 and Unger, 2006), SWIFT-membership (see Walker, 1999 and Unger, 2006) Egmont Group-membership (Unger, 2006) and/or blacklisted countries by the FATF (see Masciandaro and Portolano, 2002). In order to avoid the use of a single indicator, all the available information of the anti-money laundering policy of a country from the mutual evaluation reports of the FATF, IMF and World Bank is used (FATF, 20022006). This gives a unique indicator which encompasses all the different aspects of antimoney laundering policy. Creating this indicator gives the possibility to test the suspected and guessed effects of money laundering (policies) and give a empirical solid back-up, which is needed (Dilulio, 1996, p.3) and lacking (Unger, 2006, p.102) at the moment.

In response to an increasing concern over money laundering and the threat to the banking system and financial institutions, the FATF had to develop, adopt and implement measures to counter money laundering. In 1990 the FATF implemented a series of forty recommendations ${ }^{11}$ that governments should make use of to ensure that effective anti-money laundering programmes are in place. However, not all countries are members of the FATF, and therefore the forty recommendations were not implemented globally until 2001, when they were executed by the IMF and the World Bank. With their global membership the IMF and World Bank could assure a more uniform and widespread application of the recommendations, unlike the FATF with its voluntary membership. (Arnone and Padoan, 2006)

The FATF's forty recommendations should, in case they are all fully implemented, provide a country with a complete framework for successfully combating money laundering.

\footnotetext{
${ }^{11}$ Although the combat against terrorist financing is also included in this document with the 9 special recommendations, this paper will concentrate solely on combating money laundering.
} 
These recommendations include, amongst others, the definition of money laundering and the predicate crimes for laundering, the sectors that should be monitored more intensely, and the regulatory institutions and international co-operation needed. ${ }^{12}$

When conducted in the same way, with the same rules, these assessments are a good way to develop an indicator on the degree of anti-money laundering policy in a certain country. However, the analyzed assessments were different in quality, shape and size. The length of the reports differed from 14 pages for Germany to 361 pages for France. There were assessments that used an old style of reporting, and there were assessments according to the new style of reports, called the detailed assessments. As Arnone and Padoan (2006) concluded: "As a result of the way the assessments were made and even their layout, the assessments differed widely in quality, content, layout, and even across institutions and countries, making it very difficult to make sensible cross-country comparisons and analysis."

The FATF's procedure is to assess countries on the degree of compliance with the forty recommendations. These assessments are public and are published as mutual evaluation reports on the FATF website or on the websites of FATF-style regional bodies ${ }^{13}$. These assessments include a full description of the way a country tries to combat money laundering and, in later versions ${ }^{14}$ a table with scores for these forty recommendations. These scores vary between fully compliant (FC), largely compliant (LC), partly compliant (PC) and not compliant (NC) and include the possibility of a not applicable (NA) score. A table such as this gives a good overview of the strengths and weaknesses of the anti-money laundering policy of each country. When evaluating these scores, the FATF takes the financial possibilities for that specific country into consideration. This means that the same policy could be assessed as an LC for a developing country, while it is assessed as a PC for a developed country.

The problem with this method of evaluation is that the scores are not comparable across countries. In the past, countries took initiatives to compare themselves to others. Cyprus, for instance, compared its anti-money laundering and terrorist financing framework with eight other countries: Australia, Belgium, Hungary, Ireland, Norway, Slovenia, Sweden and Switzerland. Based on the scores of the mutual evaluation reports of the countries, Cyprus found itself on the top of the list, as best compliant country. The country proudly declared

\footnotetext{
12 This short description provides an extreme simplification of the recommendations. For the complete text of each recommendation, see the forty recommendations published by the FATF on its website or see the short description of the recommendations in appendix I.

${ }^{13}$ There are 9 FATF-style regional bodies which represent 9 different regions; AGP (Asia/Pacific Group), CFATF (Caribbean FATF), Council of Europe (MONEYVAL, Eastern Europe), EAG (7 Asian countries), ESAAMLG (Eastern and Southern Africa), GAFISUD (Latin America), GIABA (Western Africa), MENAFATF (Northern Africa and the Middle-East) and OGBS (13 small islands and Panama)

${ }^{14}$ A new method including a table with scores was first described in February 2004; FATF (2004)
} 
these results as "a comprehensive response to the various unfounded adverse criticisms aired from time to time against Cyprus" (Central Bank of Cyprus, 2006). This comparison, however, is not valid because of the differences in countries' economic possibilities for combating money laundering.

Although all of the information on the degree of anti-money laundering policy is available in the mutual evaluation reports, the construction of a good indicator for anti-money laundering policy that can be used "to make sensible cross-country comparisons and analysis" (Arnone and Padoan, 2006) cannot be achieved by a simple calculation.

To come up with the best possible indicator on anti-money laundering policy, the creation of a database that includes all the relevant information that one can find in the mutual evaluation reports is needed ${ }^{15}$. Because the various recommendations differ so much and because there is room for different interpretations of the recommended action(s), the creation of a database started with developing six broad categories, which can be applied in general for attributing scores from 0 to $5 .^{16}$

$0=$ No policy or action performed

$1=$ Only some policy or action performed / an attempt has been made

$2=$ Still a lot to be done

$3=$ Some problems or some sectors uncovered

4 = Minor shortcomings / considerations for improvement

$5=$ Comprehensive implementation

The NA (not available) score, which was possible in the traditional FATF detailed assessments, has been excluded from the database. This makes calculations involving the scores less cumbersome and is more useful for scientific research.

After creating this index, the entire mutual evaluation reports of all the different countries $^{17}$ were read. For each country, scores were applied to all 40 different

\footnotetext{
${ }^{15} \mathrm{I}$ am aware of the fact that the reports are still in their infancy. In 2005, the IMF evaluated 23 reports with regard to their overall quality, deficiencies in description/analysis, recommendations and ratings and found that $48 \%$ of the recommendations and $49 \%$ of the ratings contained material with serious deficiencies. This means that there is still a long way to go in order to assess countries' anti-money laundering activities properly. There is hope that the efforts of the IMF and FATF will improve the quality of the mutual evaluation reports in the future, since they play an important role in the international fight against money laundering nowadays.

${ }^{16}$ It is worth mentioning that some recommendations have a deviant character, which means that in case the wording cannot be applied literally, a somewhat freer interpretation of the general index is needed.

${ }^{17}$ There are 17 countries in the sample: Australia, Austria, Belgium, Denmark, France, Germany, Greece, Ireland, Italy, Luxembourg, Netherlands, Norway, Portugal, Spain, Sweden, United Kingdom and the United States of America. This selection is based on the availability of mutual evaluation reports, the availability of
} 
recommendations and it was noted exactly which comments and phrases made that specific score reasonable. ${ }^{18}$ Using this method, a database is created with a score for each country and each recommendation, including the argument(s) as to why this score is chosen and a reference to the source of the argument(s) in the mutual evaluation report. Table 1 shows, as an example, the first part of the database, which includes 680 scores with arguments why these scores are attributed. ${ }^{19}$

Table 1: The Construction of the Database

\begin{tabular}{|l|l|l|l|}
\hline ISO & $\mathbf{R}$ & $\mathbf{F}$ & Final score is based on: \\
\hline AUS & 1 & $\mathbf{4}$ & $\begin{array}{l}\text { (7) Predicate offences include all indictable offences (8) Criminalised at state and territory } \\
\text { level, and these offences vary in comprehensiveness }\end{array}$ \\
\hline AUT & 1 & $\mathbf{3}$ & $\begin{array}{l}\text { (120) Palermo not implemented and ratified (Table 10 - sentence 3) Raise penalty level for } \\
\text { simple ML offences }\end{array}$ \\
\hline BEL & 1 & $\mathbf{5}$ & (7) Ok \\
\hline DAN & 1 & $\mathbf{4}$ & (Table) Greenland and Faroe not fully consistent, range of predicate offences not adequate \\
\hline FRA & 1 & $\mathbf{5}$ & (149) Palermo + Vienna implemented, Criminalization extensive \\
\hline GER & 1 & $\mathbf{5}$ & (6) Criminalized on basis of Palermo and Vienna \\
\hline GRE & 1 & $\mathbf{2}$ & (140) Expand ML to all serious offences and dual criminality \\
\hline IRE & 1 & $\mathbf{5}$ & (7) Broad ML offence (prosecution + conviction level remain low) \\
\hline ITA & 1 & $\mathbf{5}$ & (In text and table no indications for deduction of points have been found) \\
\hline LUX & 1 & $\mathbf{2}$ & (7, Table 2, 22) Palermo not ratified, scope too limited \\
\hline NLD & 1 & $\mathbf{4}$ & (113) Palermo not implemented \\
\hline NOR & 1 & $\mathbf{4}$ & (4) Minor enhancements should be made regarding self laundering and conspiracy \\
\hline
\end{tabular}

Source: Constructed by Ferwerda and Bosma in 2007. ISO =ISO-country code, $R=$ Recommendation number and $F=$ Final score (the paragraph numbers or table numbers where the argument is found are given between brackets) 20

The entire table with all scores attributed according to the process described above immediately gives an indication which country has the most comprehensive and complete anti-money laundering framework. It also reveals exactly which of the forty recommendations a country is less compliant with and why. For a detailed analysis of the results of this evaluation process, see Unger and Ferwerda (2008).

Arnone and Padoan (2006) evaluated the method described above by comparing its results with the figures that they found when using the scores in the detailed assessments (these are the FATF scores, which are quantified by Arnone and Padoan). Because their

(comparable) crime data and because money laundering worldwide is "heavily concentrated in Europe and North America" (Walker, 1999, p.25)

${ }^{18}$ The application of scores based on text is always subject to interpretation, which could result in measurement errors. To reduce this to the minimum, the final score was based on a discussion of two researchers that applied a score separately, which means that if one came up with a 5 and the other with a 3 , this did not mean that the final score automatically became 4. In principle, it could actually happen that the final score was 0 (Ferwerda and Bosma 2007a).

${ }^{19}$ Since the arguments for every score were included in the database, it was possible to ensure consistency of the applied scores by analyzing the scores of each recommendation afterwards.

${ }^{20} \mathrm{I}$ am grateful to Silvester Bosma for allowing me to use the database that we created together. 
figures are based on the detailed assessments, only six of the 17 countries could be compared; for the other countries there were no detailed assessments available. They have figures for only the following countries: Australia, Belgium, France, Ireland, Italy and Sweden. ${ }^{21}$ From the aggregated scores of the different countries it was concluded that "the results are very similar". In both rankings, France and Belgium are the best performers and Australia and Sweden the worst, leaving Ireland and Italy in the middle. The difference in ranking is that Ireland and Italy are switched in order, just like Australia and Sweden. However, both scales are so close to each other that they almost appear indistinguishable.

The recommendations have been divided in different anti-money laundering policy areas to be able to identify the effects of the different policy areas: legal, private sector, public sector and international cooperation. ${ }^{22}$ The policy area 'legal' covers the aspects of the legal system of a country, which are for instance on the criminalization of money laundering, the criminal liability of legal persons and the possibility to confiscate criminal proceeds. ${ }^{23}$ The 'private sector' part of anti-money laundering policy includes mainly the duties (especially reporting) of private companies, like financial institutions and 'designated non-financial businesses and professions'. ${ }^{24}$ The category 'public sector' is on the institutional set-up needed for the fight against money laundering, like the establishment of a financial intelligence unit, regulation and supervision. ${ }^{25}$ 'International cooperation' in the fight against money laundering, includes among others implementing different conventions, mutual legal assistance and extradition. ${ }^{26}$ The scores on these policy areas for the 17 countries in the dataset are shown graphically in figure 3. This figure is included to show the variation in the different policy areas between countries, and is not discussed in full detail in this paper. One can see that there is more variation between countries on the 'legal framework' and 'duties of the private sector' compared with the variation between countries on the 'institutional framework' and 'international cooperation'. The effect of the different policy areas is

\footnotetext{
${ }^{21}$ This was true at the time of the analysis; meanwhile this number has increased, and could increase even more in the future.

${ }^{22}$ The score for every policy area is the sum of all the applicable recommendations; this means that the same importance for every recommendation is assumed. This is not true per se; it could be that some recommendations are more important or that a combination of some recommendations is needed for an effective anti-money laundering policy. It could also be that the chain is only as strong as its weakest link and that neglecting one specific recommendation could destroy the entire anti-money laundering effort. However, as a first step it seems reasonable to assume that all recommendations are of the same importance. Weights can be attributed at a later time, once more about the interaction of the recommendations is known.

${ }^{23}$ The score for this policy area is the sum of the scores for recommendations 1 till 4.

${ }^{24}$ The score for this policy area is the sum of the scores for recommendations 5 till 13, 15 till 18, 23 till 25 , recommendation 14 and 20 are dropped due to no/hardly any variation in the scores for the 17 countries included in the dataset.

${ }^{25}$ The score for this policy area is the sum of the scores for recommendations 19 and 26 till 34

${ }^{26}$ The score for this policy area is the sum of the scores for recommendations 21, 22 and 35 till 40
} 
estimated separately, which makes only the variation within a policy area important for the empirical result.

Figure 3. The percentage of compliance by anti-money laundering policy areas

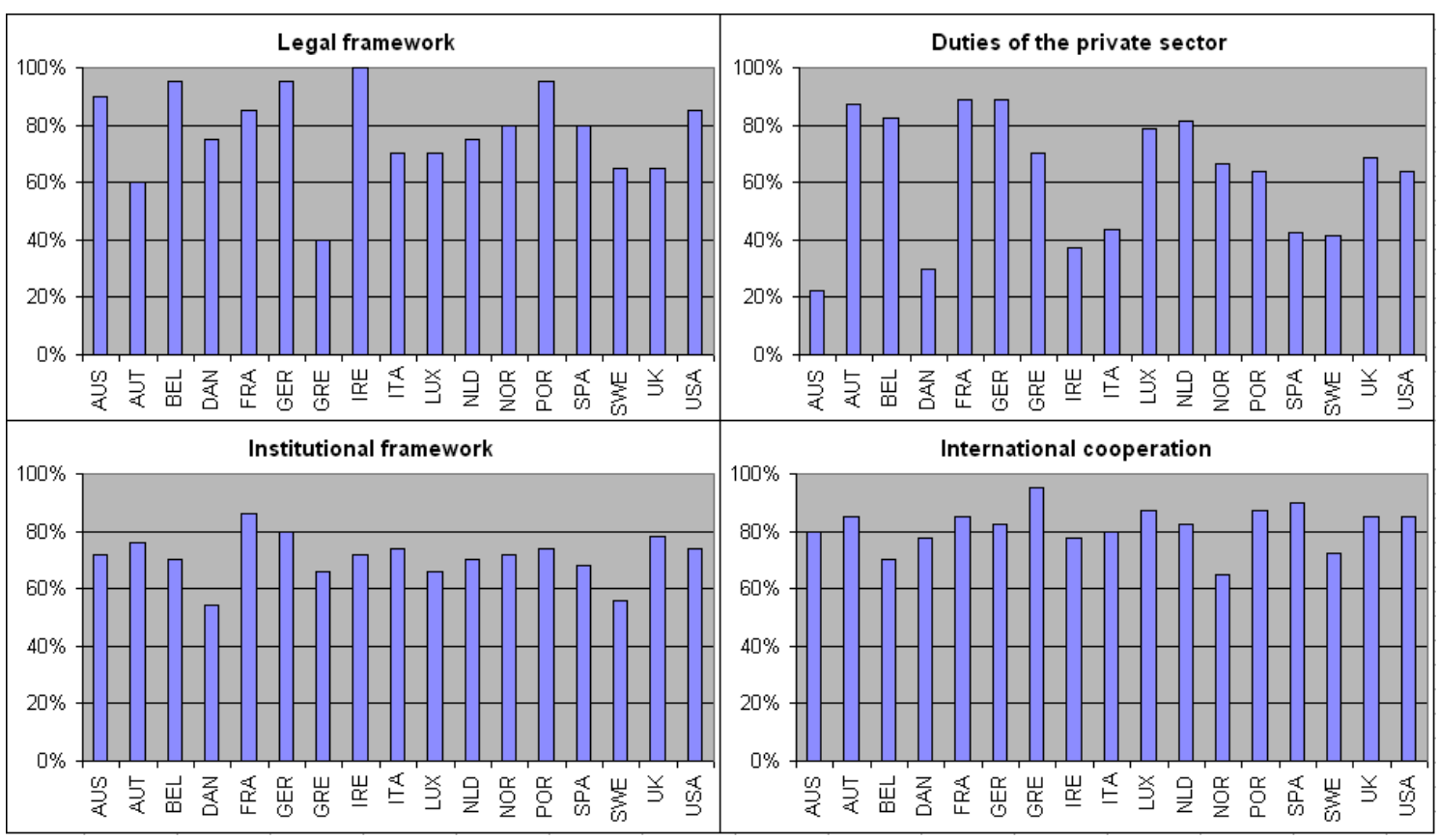

Source: calculated by the author. Since the number of recommendations differs for every policy area, percentages are used. There are, for example, four recommendations on the legal aspects of anti-money laundering policy, and therefore the best possible score is 20, so the United States has $85 \%$ compliance with this policy area with 17 points out of 20 .

\section{Empirical Results}

Since the number of countries is limited, panel data will be used for the empirical estimation, although the variables on anti-money laundering policy are time invariant. To be able to estimate the effect of the time invariant variables, a Mundlak (1978) specification is used instead of the less efficient but more consistent fixed effect model. In practice this means that the average of all the time varying variables is included in the model to deal with the correlation between the country specific variable (areas of anti-money laundering policy in this case) and all other right hand side variables. The parameters of the Mundlak specification are the same as the random effects model with the same variables, but have higher t-values.

As outlined above, the model will consist of a time varying dependent variable (crime) and independent variables which are time invariant (anti-money laundering policy) and time variant (GDP per capita). This brings us to the following estimation model: 
Crime $_{c t}=\beta_{0}+\beta_{1}$ Legal $_{c}+\beta_{2}$ Private $_{c}+\beta_{3}$ Public $_{c}+\beta_{4}$ International $_{c}$

$+\beta_{5} \log (G D P p / c)_{c t}+\beta_{6} \log (G D P p / c)_{c}+U_{c t}$

$$
\begin{array}{ll}
\text { Crime }_{\mathrm{ct}} & =\text { Total crime rate of country } \mathrm{c} \text { at time } \mathrm{t} \\
\text { Legal }_{\mathrm{c}} & =\text { Legal framework to fight money laundering } \\
\text { Private }_{\mathrm{c}} & =\text { Duties of the private sector to fight money laundering } \\
\text { Public }_{\mathrm{c}} & =\text { Institutional framework to fight money laundering } \\
\text { International }_{\mathrm{c}} & =\text { International cooperation to fight money laundering } \\
\log (\mathrm{gdp} p / \mathrm{c})_{\mathrm{ct}} & =\text { GDP per capita } \\
\log (\mathrm{gdp} \mathrm{p} / \mathrm{c})_{\mathrm{c}} & =\text { Average GDP per capita } \\
\mathrm{U}_{\mathrm{ct}} & =\text { Standard error term for panel data }
\end{array}
$$

One might suspect the problem of multicollinearity here, since the different policy areas can be highly correlated. To show that this is not the case, the correlation matrix is shown here.

Figure 4. The correlation matrix of the four different policy areas

\begin{tabular}{|l|l|l|l|l|}
\hline Correlation & Legal & Public & Private & International \\
\hline Legal & 1 & & & \\
\hline Public & 0.31 & 1 & & \\
\hline Private & -0.11 & 0.53 & 1 & \\
\hline International & -0.36 & 0.21 & 0.2 & 1 \\
\hline
\end{tabular}

Using a standard OLS-estimation procedure with a Mundlak specification gives the following result:

$$
\begin{aligned}
& \text { Crime }_{c t}=20772-287 \text { Legal }_{c}-29 \text { Private }_{c}+5 \text { Public }_{c}-518 \text { International }_{c} \\
& \begin{array}{llll}
(-1.19) \quad(-0.45) \quad(0.02) \quad(-2.33) *
\end{array} \\
& +391 \log (G D P p / c)_{c t}+4671 \log (G D P p / c)_{c} \quad \text { [adjusted } \mathrm{R}^{2}: 0.47 \text { ] } \\
& \text { (0.41) (2.19) (t-statistics between brackets) } \\
& \text { * = significant at a 5\%-level }
\end{aligned}
$$

\footnotetext{
${ }^{27}$ Source: Penn World Table (Heston, Summers and Aten, 2002)
} 
Three of the four effects have the expected negative sign. The one with a positive sign is neither statistically nor economically significant. The significant effect found in this estimation is that international cooperation to fight money laundering indeed does, as outlined in the theoretical model, decrease the crime level. The fact that international cooperation has a statistically and economically significant effect might not be that surprising: money laundering is seen as a crime which is transnational to a large extent and therefore needs cooperation at an international level to combat it. The hypothesis that anti-money laundering policy can be used to reduce the crime level can be accepted, with the specification that it is especially the international cooperation in the fight against money laundering which is important for reducing crime. ${ }^{28}$ So the efforts of the international organisations (like UN, FATF, IMF and the World Bank) have to be seen positively and should be considered as an important instrument to decrease not only the amount of money laundering world wide, but also the crime level.

\section{Further Research}

The value of the empirical result is not so much the specific outcome outlined above, but the fact that the four indicators developed here can be used for further more extended empirical research. Further empirical tests will have to examine whether the hypothesis can also be confirmed when including more countries in the dataset or when using more control variables. Further research that can test the causality of the effect, by using instrumental variables, would have a lot of added value. There is hope that the efforts of the IMF and FATF will improve the quality of the mutual evaluation reports in the future, which will lead to an improvement of the results of the research methodology that is described in this paper.

\section{Conclusion}

The effect of the fight against money laundering can be modeled using the economics of crime as a starting point. The economics of crime and money laundering, developed in this paper, show that the crime rate in a country can be reduced by: increasing the probability to be caught for money laundering and the predicate crime, increasing the punishment of money laundering, and by increasing the transaction costs of money laundering. With the assumption that these factors are all positively influenced by a stricter anti-money laundering policy the

\footnotetext{
${ }^{28}$ The results are quite robust, except for the inclusion of recommendation 12 . Using a random effects model with the same variables also gives a significant effect on a $5 \%$ level, with the same estimated parameter by construction.
} 
hypothesis empirically tested in this paper is that anti-money laundering policy deters potential criminals from illegal behavior and therefore lowers the crime rate. Since the data on anti-money laundering policy, used in the literature so far, is not all-embracing, a unique indicator is constructed by the author. This indicator is constructed by using all the information from the mutual evaluation reports of the FATF, IMF and World Bank. This gives unique data on anti-money laundering policy which can be used to estimate the often mentioned and suspected effects of money laundering (policies) and provide these with a solid empirical back-up, which is needed and lacking at the moment. This data is used in an empirical estimation based on a Mundlak specification to test the economics of crime and money laundering. The empirical estimation shows that the crime level in a country can be reduced by improving anti-money laundering policies, especially if it focuses on international cooperation. This is most likely due to the international character of money laundering. This result should be an extra incentive for countries and international organizations to continue (or start) with their efforts to promote and develop the international cooperation in the fight against money laundering to decrease the amount of money laundering and crime world wide. 


\section{Literature}

Arnone, M. and P.C. Padoan (2006) Anti-Money Laundering by International Institutions: A Very Preliminary Assessment, Paper presented at the Conference 'Corralling the economy of crime and money laundering: A challenge for banks and international institutions into the $21^{\text {st }}$ century', 28-30 September 2006

Becker, G.S. (1968) Crime and Punishment: An Economic Approach, Journal of Political Economy, Vol 76, pp. 169-217

Bentham, J. ([1788] 1843) Principles of Penal Law, Works, Vol. 1, p. 399 ff

Camdessus, M. (1998) Money Laundering: the importance of International Countermeasures, Plenary meeting of the FATF, Paris

Central Bank of Cyprus (2006) Council of Europe's assessment report on Cyprus' measures and systems for the combating of money laundering and terrorist financing, published on the website of the Government of Cyprus: www.cyprus.gov.cy

Dilulio Jr., J.J. (1996) Help wanted: Economists, Crime and Public Policy, The Journal of Economic Perspectives, Vol. 10, No. 1, p.3-24

Duyne, P. C. van (2003) Money laundering, Fears and facts, in: Duyne, P.C. van, Lampe, K. von \& Newell, J.L. (Ed.), Criminal Finances and organizing crime in Europe, Nijmegen: Wolf Legal Publishers, p. 67-104

Eide, E. (2000) Economics of Criminal Behavior, in: Encyclopedia of Law and Economics, ed. by B. Bouckaert, and G. De Geest, vol. 5, pp. 345-389. Cheltenham: Edward Elgar.

FATF (2002-2006) Financial Action Task Force on Money Laundering, the Mutual Evaluation Reports on Anti-Money Laundering and Combating the Financing of Terrorism of Australia (Oct 2005), Austria (Nov 2003), Belgium (Jan 2005), Denmark (Mar 2006), France (Apr 2004), Germany (May 2003), Greece (May 2005), Ireland (July 2005), Italy (Apr 2005), Luxembourg (Nov 2003), Netherlands (Dec 2003), Norway (Jan 2005), Portugal (Mar 2006), Spain (Sep 2005), Sweden (Sep 2005), United Kingdom (Dec 2002) and United States of America (May 2006), published on the FATF website: www.fatf-gafi.org

Heston, A., R. Summers and B. Aten (2002) Penn World Table Version 6.1, Center for International Comparisons at the University of Pennsylvania (CICUP), October 2002.

Masciandaro, D. (1999) Money Laundering: The Economics of Regulation, European Journal of Law and Economics, Vol. 7, p. 225-240

Masciandaro, D. and A. Portolano (2002) Terrorism and Organised Crime, Financial Regulation and Non Cooperative Countries: Inside the Black (List) Box, University of Lecce Economics Working Paper, No. 32/14

Mundlak Y. (1978) On the Pooling of Time Series and Cross Section Data, Econometrica, Vol. 46, No. 1, p. 69-85 
Takáts, E. (2006) A Theory of "Crying Wolf": The Economics of Money Laundering Enforcement, Paper presented at a workshop organized by Donato Masciandaro at Bocconi University, Milan, March 2006

Unger, B. (2006) The Amounts and Effects of Money Laundering, Dutch Ministry of Finance report, with the collaboration of G. Rawlings, M. Siegel, J. Ferwerda, W. de Kruijf, E. M. Busuioc and K. Wokke

Unger, B. and J. Ferwerda (2008) Regulating Money Laundering and Tax Havens: the Role of Blacklisting, prepared for the European Consortium for Political Research (ECPR) conference; (Re)Regulation in the Wake of Neoliberalism, Consequences of Three Decades of Privatization and Market Liberalization, Panel: Naming and Shaming, held at Utrecht University, 5-7 June 2008

Walker, J. (1999) How Big is Global Money Laundering?, Journal of Money Laundering Control, Vol. 3 No. 1

\section{Appendix I. Short description of the different recommendations}

\begin{tabular}{|l|l|}
\hline Recommendation & Short description / keywords regarding the content ${ }^{29}$ \\
\hline 1 & Criminalize ML, on basis of Palermo/Vienna Convention \\
\hline 2 & Prove ML, apply to legal persons and penalties \\
\hline 3 & Make confiscation of ill-gotten gains possible \\
\hline 4 & No secrecy laws \\
\hline 5 & Consumer Due Diligence (CDD), know your customer \\
\hline 7 & Special CDD for Politically Exposed Persons (PEPs) \\
\hline 8 & Special CDD for cross-border correspondent banking \\
\hline 9 & Monitor for new developments leading to anonymity \\
\hline 10 & Rely on third parties for CDD \\
\hline 11 & Record-keeping \\
\hline 12 & Special attention to complex, unusually large transactions \\
\hline 13 & CDD for Designated Non-Financial Businesses and Persons (DNFBP) \\
\hline 14 & Report to Financial Intelligence Unit (FIU) \\
\hline 15 & Employee protection and professional secret \\
\hline 16 & Financial Institutions (FI) develop internal policy, training and audit \\
\hline 17 & R. 13-15 and R. 21 for DNFBPs \\
\hline 18 & Sanction possibility for non-compliance \\
\hline 19 & Shell banks should be prohibited \\
\hline 20 & One central database for currency transactions \\
\hline & Recs to all businesses \& development techniques money management \\
\hline
\end{tabular}

\footnotetext{
${ }^{29}$ Descriptions and keywords are subjective and should not be used as an official guideline, but rather as a
} mnemonic device. 


\begin{tabular}{|l|l|}
\hline 21 & Special attention business relations transactions with NCCTs \\
\hline 22 & Special attention to branches located abroad, especially NCCTs \\
\hline 23 & Regulation, supervision and licensing FI \\
\hline 24 & DNFBPs should be supervised \\
\hline 25 & Establish guidelines and feedback \\
\hline 26 & Establish a FIU \\
\hline 27 & Responsibility and develop new techniques for law enforcement \\
\hline 28 & Ability to obtain information by competent authorities \\
\hline 39 & Supervisors should have adequate powers \\
\hline 31 & Adequate resources for competent authorities \\
\hline 32 & Domestic cooperation between FIU, law and supervisors \\
\hline 33 & Review effectiveness with statistics \\
\hline 34 & Prevent unlawful use legal persons (bearer shares / beneficial owner) \\
\hline 35 & Special CDD to trust offices \\
\hline 36 & Become party of and implement specific conventions \\
\hline 37 & Provide range of Mutual Legal Assistance (MLA) \\
\hline 38 & Dual criminality \\
\hline 39 & Respond to foreign request to freeze, seize and confiscate \\
\hline 40 & Recognize ML as extraditable offence \\
\hline & International cooperation with counterparts \\
\hline
\end{tabular}

